\title{
EDITORIAL: OCIO Y JÓVENES
}

\author{
Manuel Cuenca Cabeza ${ }^{1}$ \\ Juan Manuel Carreño Cardozo ${ }^{2}$
}

La revista Lúdica Pedagógica presenta esta edición sobre el tema "ocio y jóvenes", como producto de una interacción con la Asociación Iberoamericana de Estudios de Ocio (отIUM). Esta asociación promueve la investigación, la formación, el desarrollo y difusión de estudios del ocio y temas afines. Como parte de su quehacer, se fomenta la producción científica sobre el ocio, de forma que se divulguen los avances y propuestas desde diferentes perspectivas, teniendo en cuenta el amplio bagaje que en la actualidad gran cantidad de autores e investigadores aportan en Iberoamérica.

El ocio, la recreación, el tiempo libre, la lúdica, el juego y el turismo son temas de estudio que se han desarrollado académicamente con especial fuerza en las últimas décadas. Por eso, para la revista Lúdica Pedagógica es pertinente hacer parte de los desarrollos investigativos que jalonan los campos académicos hacia aspectos innovadores.

Especialmente, este número se dedica al tema "ocio y jóvenes", como preocupación por las formas en que en el campo se comprenden las múltiples experiencias que en este tiempo se dan desde el ocio. En este sentido, son los jóvenes quienes conviven con diversidad de formas de expresión, actuación y relaciones en las cuales se pone en juego el ocio. Los jóvenes son atravesados fuertemente en su experiencia por formas convencionales de entretenimiento y diversión, cuya dinámica cambiante y de base comercial es difícil de comprender para otras generaciones. A su vez, los jóvenes trascienden de varias maneras el solo divertimento y constituyen procesos identitarios, de organización social, formativos, entre otros, que manifiestan el diálogo con estos contextos de ocio, conjugados con situaciones particulares de su experiencia y de las sociedades a las que pertenecen.

El imaginario sobre varios aspectos de los jóvenes ha orientado muchas opiniones que prejuzgan sus prácticas o consideraciones sobre sí mismos. Temas como los videojuegos, el uso de teléfonos móviles, la pertenencia a barras de fútbol, la vivencia de la calle, entre otros, son tópicos que desde los estudios de ocio se comprenden como complejas redes de relaciones que interpretan el contexto juvenil a partir de sentimientos, sueños, deseos, carencias, y el sinfín de elementos que se involucran

1 Catedrático Emérito de la Universidad de Deusto y Fundador del Instituto de Estudios de Ocio (Bilbao, España), promueve el desarrollo de las redes de investigación Otium y OcioGune. Correo electrónico: mcuenca@deusto.es

2 Docente de planta de la Universidad Pedagógica Nacional. Correo electrónico: jcarreno@pedagogica.edu.co 
con sus propias características personales y sociales. También se demuestra, a través de experiencias en colegios, grupos juveniles, organizaciones barriales, entre otros, que los jóvenes tienen hondas preocupaciones por su formación y el bienestar de sus contextos.

Más allá del conocimiento sociológico de las prácticas, el ocio de los jóvenes no es solo resultado de su edad o su contexto social, sino que también está relacionado con las experiencias y conocimientos anteriores, al tiempo que proporciona los fundamentos de los hábitos de ocio del futuro. De ahí que al estudiar la relación entre ocio y desarrollo juvenil sea necesario reflexionar desde diferentes ángulos. El ocio que experimentan los jóvenes forma parte de un presente que se transforma con los cambios biológicos y contextuales propios de la vida. Aun así, se sabe que las aficiones juveniles son perdurables en la medida que alcanzan un determinado nivel de competencia técnica y dan acceso a disfrutes que se abren hacia retos de superación.

Esto hace que podamos hablar de un ocio que potencia o inhibe el desarrollo personal, considerado desde el punto de vista del crecimiento mental, físico, social o emocional. Es factible diferenciar un ocio juvenil incipiente de otro más maduro, sin perder por ello la identidad propia de la edad, diferenciada del ocio de los niños, los adultos o las personas mayores. Por estas y otras muchas razones, el ocio de los jóvenes es un tema candente; no solo por la preocupación social ante sus manifestaciones más nocivas, sino también por la patente carencia educativa sobre los temas de ocio en este periodo vital. La educación del ocio de los niños y jóvenes está abandonada al criterio, normalmente poco formado, de sus padres, así que no es solo una cuestión personal y familiar, sino un tema de un profundo calado social.

Las apuestas investigativas que aquí se presentan son muestra de avances en dirección a la comprensión del ocio, no solo como experiencia susceptible de ser interpretada, sino como posibilidad de desarrollo humano. A partir de esta perspectiva, es relevante considerar el ocio como eje de formación que involucra el continuo distanciamiento del produccionismo monetario y la acumulación de bienes como medio y propósito de la felicidad en nuestra especie. A la vez, hablar de formación de o para el ocio relaciona nuevas maneras en que la sociedad gestiona los tiempos, se preocupa por la sostenibilidad ambiental, cuestiona la inequidad social y, en últimas, propende por una mejor humanidad. Ocio tiene lugar en la subjetividad e intersubjetividad que sustenta experiencias vinculadas a proyectos de felicidad de las sociedades, por esta razón, estudiarlo requiere avanzar en interpretaciones e intervenciones actuales, acordes con las dinámicas de una época de consumo y aparente deshumanización que acelera la velocidad para producir dispositivos masivos de entretenimiento y control.

Los escritos de esta sección central son referencias que esperamos sirvan para nuevas proyecciones en los estudios de ocio, cuyas miradas se pueden dirigir a contextos, poblaciones, retos o necesidades específicas. Es una forma de promover la consolidación de comunidades académicas en torno al tema del ocio, que reconozcan mutuamente los avances y también produzcan espacios de discusión y debate. 